\title{
Scenario Planning in Public Libraries: A Discussion
}

Matt Finch and Rafael Ramirez

\begin{abstract}
The authors explore the use of scenario planning in public libraries via a $Q \& A$ discussion. They discuss the impact of unexpected events and unwelcome trends on libraries' future, explain the distinction between scenario work and forecasting, and outline a practical approach to devising and delivering scenario planning activities at a local library level.
\end{abstract}

\section{Paper}

This discussion, which took place at Oxford University's Said Business School on 23 August 2018, explores the use of scenario planning in public libraries.

Rafael Ramirez is Director of the Oxford Scenarios Program and the first Professor of Practice of Oxford University. One of the world's foremost authorities on scenario planning, he is co-author of Strategic Reframing: The Oxford Scenario Planning Approach (Ramirez and Wilkinson 2016) and was keynote speaker on scenario planning for libraries at the 2018 IFLA President's Meeting (International Federation of Library Associations 2018).

Matt Finch is a consultant who specialises in strategy and storytelling for institutions, including libraries. He was the first Creative in Residence at the State Library of Queensland and is the creator of the Library Island professional development activity.

Matt:

How can scenario planning be helpful for public libraries? 
In the piece I just did for IFLA, I started with a story in the New Statesman about a public library in a village in Northern England which was being cut (Chakelian 2018).

Young mothers in the village took their kids to the library for two reasons: one, they couldn't afford the books themselves, and two, it was the best place where they could read to kids and not be disturbed by everyday family things. The library's funding was going to be cut, and the local authorities were going to amalgamate the libraries in a bigger town, and they weren't going to be able to afford the bus fare to the town.

There were three futures happening in this story. First of all, there was the future of the children, looking ahead to adulthood and what kind of citizens they will become. The public library enables parents, grandparents, perhaps schoolteachers, to enhance or secure a certain future for children and then citizens. If you go with your child or grandchild to read picture books together, and then they graduate to, say, Harry Potter, research suggests that if you start reading young, your chances of reading later in life improve significantly (Sparks, Patton, and Murdoch, 2014). Libraries enable this public ethos about reading.

So one future comes from the expectation that the library will still be there throughout childhood and beyond; if the library is suddenly cut, it doesn't matter if you acquired a good habit when you were three years old, you won't be able to reach that first future we've described.

A second aspect of this first future is of course that the librarians hope that their institution will be there, and provide them with employment; and in the same way the teachers will be happy if the whole system goes on and supports them in their work. So there's a whole bunch of futures embedded in this first future, or future system, and everybody involved in it implicitly assumed that the future they were hoping for would come to pass. 
But there are two other futures that clash with this first one: one was the financial crisis and its impacts on society now and to come, and the other was an ageing population and its consequences.

The financial crisis, in the United Kingdom, meant that the government decided to spend a large amount of money bailing out the banks, and it also ring-fenced health spending, which meant that it had to cut the money elsewhere. The politically most expedient place to make that cut was to local services, including libraries. My understanding (and I may be wrong on the detail) is that in Britain it's legally mandated to provide library services, but there are not very well defined criteria for what that level of service is; you might cut sixteen libraries down to one, for example. So one future that came in and crashed across the one expected by children, parents, and librarians and teachers was the financial crisis and the diverting of money from local public services to saving the banks. This kind of future, which erupts in this way, we call an event.

The other future which came to bear on the situation, and diverted resources from children's services at the library, is an ageing population. This means, basically, that since 75 -year-olds vote and 12 -year-olds don't, more and more public resources get diverted to caring for the elderly rather than for the young.

This is a second type of future, which we can refer to as 'boiling frog syndrome': they are manifested as trends which are slow and emerging, such as an ageing population or climate change. If they come together with other trends, and an event like the financial crisis, they bring about a different future than the one which the library constituents were counting on. These trends and events are often from sectors of society which are connected to, but distinct from, the library sector itself - the banking system, the rise of Google and yet they erupt into your own sector, making the trend you were expecting to ride on forever unavailable to you.

Scenario planning is helpful to public librarians because there is some evidence that being attentive to future events, trends, and conditions allows one to rehearse plans in such a way that if the alternative future 
to the one one is hoping for arises, one has a playbook of responses, making you better prepared and more able to cope.

Matt:

So a potential outcome for a scenario planning process is that you have a toolkit of contingencies and options depending on which future arises? So, for example, you've thought about seeking your own funding in case your previous funding streams dry up?

Rafael:

In lots of public sector organisations, people are making planning more resilient by making the plans more flexible and tying fewer resources into one single future. You would not put all of your eggs in one basket, instead you would commit in such a way which allowed you to reallocate resources if Scenario B happened instead of Scenario A.

In the US, the navy is looking at climate change in scenario terms ("One arm of the Trump administration thinks climate change is a security threat" 2018): if climate change happens faster than climate scientists say it might - and that's certainly within the realm of possibility - which naval facilities will flood? This is a question of the navy's capacity to fight if a lot of its bases are underwater.

Matt:

At the State Library of Queensland, we had a very well-regarded and well-funded program called First Five Forever, which supported literacy development in early childhood (State Library of Queensland 2018). As the funding cycle approached an end, coinciding with elections in state government, we workshopped creative strategic contingencies that would maintain the program even in a radically different or reduced funding environment. As it happens, after the election, the funding was continued and we didn't need to implement some of the more radical ideas, but we still learned from taking a critical, constructive look at the existing service. 
The future we were preparing for didn't come to pass, but it was worth anticipating. Is this what distinguishes scenario planning from forecasting?

Rafael:

Typically in forecasting, you have some data from the past, and some distribution of those points; you take a model of that data and its distribution and then you cast forward and pretend that tomorrow is going to be like the past. How many librarians will you need next January, premised on how many librarians have been required over the last ten years of Januaries?

That works very well if you are confident that tomorrow is going to be like yesterday. Scenario planning looks at the other side of the future, where you're not confident that the future will be similar to the past.

There is a confusion here between probability and plausibility. Scenario planning comes into play when there's no pattern from which you can forecast, and then you must go from forecasting and probabilities to scenarios and plausibility. These are visions of the future to inform the present, rather than extensions of the past into the future, as is the case in forecasting.

In the movie Zero Dark Thirty (2012), about the hunt for Osama Bin Laden, there's a scene where intelligence personnel are assembled in a room with all the data, and the boss asks them, "What is the probability that Bin Laden is there?" They offer different percentages of probability - but from an academic point of view, that's the wrong question, because there's no precedence in the data and you can't put probabilities on events that are one-offs. You can ask, "Is it plausible that he's there? Are you confident that he's there?" In forecasting, you can put a probability that next January, there's a 95\% chance we'll have this much demand on our library service, compared to the past ten Januaries; but in scenario planning we're looking at 
situations more like, what could happen after Brexit and Europe, or after the end of Trump and Putin's political careers?

Matt:

It seems that in turbulent times, experience can lose value, because the turbulent conditions ahead will not resemble what has gone before.

Rafael:

The poster child for that is the CEO of Lehman Brothers, who, at the time Lehman Brothers went under, was the most experienced CEO in Wall Street. Experience did not seem to be an asset, or at least was correlated with liability.

Matt:

The question of plausibility interests me; in some of the work I've been doing lately with law librarians, we've been considering the different between probability and plausibility, especially in terms of how you argue the case in a court of law.

There's a famous example: if you are knocked down by a bus, and Company A runs more than half the buses in your town, then in the absence of other evidence, the probability is that you were knocked down by a Company A bus - but no court would find the company liable on such a basis, instead you have to tell a story about what plausibly happened.

Rafael:

John Kay writes about this (2013): what is the weight of plausibility in determining these decisions? He extends that from the courtroom to other decisions - in this case, for public librarians - where plausibility and a credible story matter more. 
Matt:

How do you assess the plausibility of a scenario?

Rafael:

This is a big topic; the trouble is, plausibility is a very easy concept to manipulate (Ramirez and Selin 2014). Think about the notion of 'plausible deniability', where officials can deny knowledge of or responsibility for actions taken within their organizational hierarchy; plausible deniability is what the rest of us call lying. The etymology of plausibility is "that which deserves applause".

So there is an ethical dimension to plausibility - you don't want to make it manipulative. Plausibility cannot be reached by individuals alone, it needs disagreement, argument, and counter-argument in a way that is constructive. You assess the assumptions that others are making of the future, and they are invited to do the same for you, and to contrast those assumptions.

Part of the challenge of doing plausibility rigorously is who you invite into the conversation.

Matt:

If a public library director wants to use scenario planning to look at their service, how might they begin to think like a scenario planner?

Rafael:

First, you need a user. Is it yourself? The city which funds you? Your staff? The process requires a purpose, a use for the scenarios you will generate.

Matt:

Could it be the community themselves? 
Rafael:

Potentially, but they would need to have a really concrete action ahead of them - for example, a vote on the allocation of city funds. If you don't have a user, or a use, then the work becomes useless: a significant chunk of your investment in scenario planning is to assess how the scenarios will inform a decision, a process, a debate, or a public position on something.

If you were using scenarios to determine your library's future workforce requirements, it would be a different set of scenarios to if you were figuring out what architects the municipality should hire for the new library branch, or a negotiation with Google about digitisation of collections.

Matt:

Should scenario planning always be formed with a specific question in mind? Can you use it to generate, say, a strategic plan for a 5-10 year period?

Rafael:

Yes, but you need to have, not so much a question or a focus point, but a use and a user. These could be someone in the press and or media, because you want to find the right story to wow them and raise your profile; or it might be that if you're addressing employment issues, you could create scenarios with a public sector union collaboratively, or you could do it independently to present scenario options to that union's representatives.

Depending on what your use is, you produce scenarios that help your user to think through the context of what they're planning to do - municipal politics, changes in the community, the demographic profile, and so on. Then you'd hope they would build a strategy that can become adapted to different futures easily

So, for example, at the McMaster University hospital in Hamilton, Ontario (Canada), they've build a halffloor between every floor with piping and so on, so that they can convert wards into operating theatres, or 
operating theatres into cafeterias or seminar rooms, within a few hours or ( $\max$ ) two or three days. Knowing that the future was uncertain for the community they served, and that medicine was evolving quickly, they built redundancy into the building so that it could be readjusted to meet different future demands. This contrasts with the inflexibility typically built into buildings, as the book How Buildings Learn (Brand 1994) shows.

The equivalent of that would be, how can one design a library as a learning system, so that it can be adjusted together with public services - police, tax and so on - and help people to become better citizens? That might mean reallocating less space for shelves and books, because the population has shifted, people that speak a different language have moved to another neighbourhood and a new set of people move in who have different requirements other than books.

Matt:

If you see public libraries as serving a community's information needs, those needs - and the media by which they are delivered - can change a lot in a relatively short period of time.

Rafael:

You have to think things through in a slightly broader way, and over a slightly longer term; and scenario planning is a good methodology to do that.

Matt:

Public libraries are very responsive institutions. The user comes in and does what they want to do, they are free to explore. The homeless person might come in for comfort and warmth and welcome, a jobseeker might use information to find employment opportunities, children come with their parents for stories and play, others use the Internet access... You can't walk into a museum and demand to see an item that's not in the exhibition; in healthcare settings, the professional's choices and opinions will largely take priority 
over the user's... Are there challenges for such a responsive institution to think ahead? How do you scan the future for public libraries?

Rafael:

Rather than being 'responsive' in the sense of being 'passive', the public librarians I have worked with think proactively and creatively about what it might mean to be a future citizen: what role might they want to play to help that future citizen, going forward?

For example, in a city where a big factory closed down, with limited opportunities for retraining or new employment, many people over fifty suddenly out of work. The librarians might look at opportunities to help these suddenly retired people to record and upload the story of that factory - enabling people to write their own story of the history of this place for future generations.

It's about being attentive to your community, and its future needs, and what roles you might have to play in meeting those needs. Beyond 'need', actually it is about ascertaining the values that hold the community together and make citizens effective and the roles librarians and their libraries can play in promoting civil values and preventing violence in all its forms from settling in.

Matt:

A forward-thinking library might not be able to predict the events that caused the factory to close, or how the town will respond to the closure, or whether another employer will come on the scene, but they have some capacity to spot opportunities and deliver.

Rafael:

They may not be able to predict, but they certainly have the capacity to imagine conversations with different sectors of the community, from the laid-off 50 year olds, to local schools, new migrants who perhaps 
don't speak English, other institutions, and always asking themselves, "What role could the library play here?"

You are attentive to possible things that the community is going to experience, and you have a playbook of possible futures which you can take to different sectors of the community and say, "This might be a good idea for us to explore together, combining our roles."

They might have a totally different idea, but you have started the conversation, you are hosting the conversation, and therefore it is to some extent now taking place on your terms. As the Economist once put it (2007), "if you're not at the table, you're on the menu"; so why not make sure the conversation happens at your table, and that you can convene those who need to converse at your table?

Matt:

So a public library service that looks to use scenario planning will need to convince their funders, and the wider community, that they should be the strategic hosts. How do you justify that cost and effort?

Rafael:

The metaphor I use is buying a television. If you don't have a lot of time, or your organisation has been cut back, you may have to do only a good-enough piece of work: like buying a cheap black-and-white television to see who has won the World Series.

If you have enough time or funds, you can buy yourself a big colour television which shows more detail about what is happening. You can put your scenarios in the local newspaper to ensure they are widely seen and widely circulated, and if you are doing that, it is worth spending more time, seeking more opinions, circulating the scenarios beforehand. To get more detail, better arguments, better references: a better, more detailed colour picture on your television. But getting started costs very little indeed. 
If you have the time, you might only do a back-of-the-envelope job, but the back-of-the-envelope job might be better than none at all.

Matt:

I love the example of using the newspaper to engage the community with your scenario planning. A library leadership team could share scenarios in the local newspaper and then give the community and other stakeholders a chance to respond.

Rafael:

If you have time, you could take those scenarios to local schools, to the old people's home, to bingo halls and sports clubs, to have discussions about them, so that by the time you go to a meeting with your funders, you can say, we've had these discussions and the community is totally in agreement that they want to avoid this future, so therefore we have a plan of how to avoid that future, and here are two other equally viable futures, our preference is for this one, what do you think? One of our alumni did scenarios for the city of Houston in Texas and aired them on the radio during commuting time.

If you do something like this, then you have set the menu of the discussion, rather than reactively working on something that has been imposed on you.

Matt:

So how do we make this work plausible, in terms of having scenarios at a very local level? How do we weigh the opinions of the schoolkids, the old people's home, our colleagues, the American Library Association, and so on? What's the yardstick for plausibility?

Rafael: 
The plausibility you seek serves one master - usefulness. If you want to persuade the city not to cut your budget by $20 \%$ but only by $12 \%$, you look at which scenarios - at least two, no more than four - best articulate the choices that need to be made and the consequences, so those who need to understand these get it. Your aim is to get people to walk through the implications and consequences of the decision they make today.

For example: "The savings you make today will be lost to you three times over in future costs of policing, juvenile detention, family breakdown, therefore this scenario is very bad value for money; however, if you resist the cuts, you might be out of line with directives at state or federal level, or the trends of your peers, but you will be making a good investment. By being courageous, you might have a bit of a fight on your hands now, but you will get a better result further down the line."

You're looking not for truthfulness, because you cannot be certain of what will happen - you are looking for two or three stories to convince people that you have thought through the alternatives, that maybe there are costs and benefits to the alternatives, and that there are certain courageous things they ought to consider doing now.

If your city is looking to cut two full time librarians in order to put money into repairing potholes, you point out to them that leaving the potholes will not create an increase in expenditure on drug rehabilitation in the next six years, but actually cutting the library might cause that.

It's about educating people in the consequences of what a decision is - not just one step, but two or three steps ahead. Assuming the politicians you report to are rational and responsible, they will go back and reconsider the options.

Matt: 
I'm also minded of the book Creating Great Choices (Riel and Martin 2017), whose methodology is about exploring two extreme options as a binary choice and then refusing to compromise, but instead finding an alternative route forward.

If I go to the council with a binary decision, that's different to offering three or four scenarios.

Rafael:

You want to set out differing scenarios which all have advantages and disadvantages. The scenario planner's job is not to make the choices, but to inform the choices, and improve the quality of decision making.

If you can help the intended user to think through the consequences, the upsides and downsides, the way the decisions are framed - a two year budget versus a five year budget for example - then a responsible statesman or woman will be thinking about their community's future, changing the conversation to address where we will be five or ten years from now.

Matt:

Is there a way public librarians can explore scenario approaches, just to get a taste or sense of what the activity is like?

Rafael:

There are lots of scenarios in the public domain that they can read. The main thing is to find someone who disagrees with them and who is reasonable; someone who has the opposite point of view, and inviting them for coffee, and asking them, what assumptions are you making about the future context of this decision? Share your assumptions, and ask them what they think.

Make that disagreement a constructive disagreement: accept that the opposite position is making assumptions about a future that could happen - even if you don't want it to - and that they have reasonably and 
responsibly thought through the consequences of those assumptions. So you say: we are both imagining plausible futures our current decisions will inhabit, we're making different assumptions, what sort of tests can we make to see if your future is unfolding, or ours is, and how we should then act.

An example of that is the Danish government, which adjust pensions based on which scenarios are happening. They meet regularly with stakeholders including unions, employers, representatives from across civil society, and demographic experts, and they look at whether the proportion of retirees versus workers is operating according to Scenario A or Scenario B, and therefore how should they act, and how much should be put into the pension pot. If it can be done at a national level, why would it not be able to be done at a local level?

Matt:

A public librarian might convincingly convene stakeholders from across a relatively small community at the local government level. Could a sufficiently entrepreneurial public librarian convene scenario planning activities for other sectors in their community?

Rafael:

Yes. Shell published an "explorer's guide to scenario planning" (2018), which is a downloadable book offering a scenario approach which you can use or adopt in different ways, accessible to all kind of community groups and institutions.

My experience of public librarians is that they would have, a priori, the role of an honest broker in the eyes of everyone else.

Matt:

This does require trust that everyone involved is acting in good faith, and behaving reasonably. Doesn't that present its own challenges? 
Rafael:

Adam Kahane, in his book Collaborating with the Enemy (2017), talks about this challenge, of working with people not only that you disagree with but you will never agree with.

How can you host a conversation where deep disagreements are acknowledged, they are considered unavoidable, in-built, and yet you continue to talk with one another?

The scenario planning approach is that you host the conversation looking back from the future into the present, not from the past into the future. This makes it easier to acknowledge disagreement, and to prevent disagreement, by listening to the other's point of view.

Matt:

How might public librarians choose a scenario planning approach and tool?

Rafael:

The approach my colleagues and I have developed is agnostic methodologically. Consultants and academics will promote different ideas of the exact method they recommend (in terms of number of steps), but the approach, to us, is like the cat's eyes on the road which prevent you from going into the ditch of bad scenario planning.

Our approach seeks to prevent your making classic mistakes, like confusing probability with plausibility, or confusing the aspects of a context they can influence with the aspects they cannot.

We always work from the aspects which the intended user cannot control - so, for a librarian: climate change, migration into your country, national-level budgets and policies are examples. The scenarios are what might happen, the strategy is what you decide to do. 
We are also very clear about the idea that scenarios are not predictions: they are for usefulness, not truthfulness, and they promote courageousness and better conversations about strategy.

Finally, we think of everybody involved in scenario planning as a learner. The people who choose to use scenario planning are those who can see themselves as learners.

Matt:

Some of those aspects are very big and broad, and someone instigating a scenario planning process might be daunted about feeling the need to research big financial trends, long term demographic movements, climate change and so on. How do we address this?

Rafael:

I think librarians are very good at reaching out for and mobilising information. They don't have to be experts on anything; they are experts on accessing information and rendering information accessible. If they need to know about how climate change could affect their own town's rivers, or trends around gun control in the US, or any issue, they will find the right source or the right author to have that conversation.

Everybody engaged in a scenario planning process is learning, and has a specific role to play. A good scenario team is made up of members who have knowledge and interests that nobody else in their team has; people who are very different from each other. We are all learning with and for each other. The host is the architect of the learning, and must be open to reviewing the chosen approach as the process proceeds, developing a local version of scenario planning for the library, or the town. The intended user has also to understand that their key t role is to learn with the help of the scenarios.

Matt:

How far should you zoom out? 
Rafael:

You should go as wide as you can afford, and as far into the future. The reason you go into the long-term future is not to divine it, but to create a point of view of the present - from the future - which is sufficiently different from the current one to help you think differently. The future is something which comes to you, which you expect to be different in the present. We in scenario planning work with the future, and come to the library saying, if this plausible future could happen, what should we prepare for, rather than assuming that the official future will come to pass.

Matt:

And sometimes that's about preparing for a future that doesn't arrive - I mentioned the contingency planning we did for First Five Forever in Australia, but we also use an activity called Library Island, which is a roleplay simulating the operation of a national library system with stakeholders and government officials as well as librarians (Finch 2018).

Strangely, we found that Library Island worked best in terms of highlighting issues and provoking creative responses when it was quite distant and different from reality, and the more closely tailored to the real world it was, the more timid participants became and less willing to try courageous experiments.

Rafael:

Part of the art of scenario planning is keeping the focus on the future before bringing it back to the present, and "I have to do this and that". You want to look at the plausible future reality of a context before you bring it back to the actionable reality of the here and now.

You spend a lot of time in a state of productive discomfort, looking at what could happen three or five or ten or twenty years from now, and what that would mean if it unfolded: what will we eat, will there be restaurants, will robots serve our food, how will people live? What kind of library would arise in that situation, 
logically as a consequence of the context? And if that could happen, what do I start doing here and now in the next budget year? You work on which problems are going to arise before you start working on the solution.

People who are in tough financial straits tend to go into action mode too early; you want to stay with the problem, and the context of the problem in the longer term, before you move into the mid-term, the shortterm, and then to the present-day action. And you want that action to be experimental and a source of learning; a source of new relationships and possibilities. That's an important benefit of scenario planning to public libraries.

\section{$\underline{\text { References }}$}

No author given. 2007. Everybody's green now. New Statesman, May 31.

No author given. 2018. One arm of the Trump administration thinks climate change is a security threat. New Statesman, February 22.

Brand, S. 1994. How buildings learn: What happens after they're built. New York, NY: Viking.

Chakelian, A. 2018. Crumbling Britain: one town's revolt against a bankrupt council to save its local library. New Statesman, May 14.

Finch, M. 2018. Library island: professional development in the land of fiction. Library Life 455.

International Federation of Library Associations. 2018. IFLA Trend Report 2018 Update. Accessed September 4, 2018. https://trends.ifla.org/files/trends/assets/documents/ifla trend report 2018.pdf 
Kahane, A. 2017. Collaborating with the enemy: how to work with people you don't agree with or like or trust. New York, NY: McGraw-Hill.

Kay, J. 2013. A story can be more useful than maths. Accessed September 4, 2018. https://www.johnkay.com/2013/02/27/a-story-can-be-more-useful-than-maths/

Ramirez, R. and Selin, S. 2014. Plausibility and probability in scenario planning. Foresight 16 (1): 54-74.

Ramirez, R. and Wilkinson, A. 2016. Strategic reframing: the Oxford scenario planning approach. Oxford: OUP.

Riel, J. and Martin, R.L. 2017. Creating great choices: a leader's guide to integrative thinking. Brighton, MS: Harvard Business Review Press.

Shell. 2008. Scenarios: an explorer's guide. Accessed September 4, 2018.

https://www.shell.com/energy-and-innovation/the-energy-future/scenarios/new-lenses-on-the-fu$\underline{\text { ture/earlier-scenarios/ jer content/par/expandablelist/expandablesec- }}$ tion 842430368.stream/1447230877395/5ab112e96191fa79e1d30c31dc6e5cd2ce19ed518a4c14 45ab32aa4c4b5c7ec5/shell-scenarios-explorersguide.pdf

Sparks, R.L., Patton, J., \& Murdoch, A. (2014). Early reading success and its relationship to reading achievement and reading volume: Replication of '10 years later.' Reading and Writing, 27(1), 189-211.

State Library of Queensland. 2018. First Five Forever. Accessed September 4, 2018. http://first5forever.org.au/

Zero Dark Thirty. [2012] 2018. DVD. Dir. Kathryn Bigelow. United States: Alliance Films. 